\title{
Exploring Principals' Physical Education Perceptions and Views from Elementary and Middle Schools of Shanghai
}

\author{
Howard Z. Zeng ${ }^{1, *} \&$ Xiaozan Wang ${ }^{2, *}$ \\ ${ }^{1}$ Brooklyn College of the City University of New York, New York 11210, USA \\ ${ }^{2}$ College of Physical Education \& Health, East China Normal University, Shanghai 200241, China \\ *Correspondence: ${ }^{1}$ Brooklyn College of the City University of New York, 2900 Bedford Ave. Brooklyn, New York \\ 11210, USA. E-mail: hzeng@brooklyn.cuny.edu \& ${ }^{2}$ College of Physical Education \& Health, East China Normal \\ University, 500 Dongchuan Rd, Shanghai 200241, China. E-mail: xiaozanwang@163.com
}

Received: September 6, $2015 \quad$ Accepted: October 23, $2015 \quad$ Online Published: November 26, 2015

doi:10.5430/wje.v5n6p37

URL: http://dx.doi.org/10.5430/wje.v5n6p37

\begin{abstract}
This study examined the status of principals' physical education (PE) perceptions, the differences between gender and school-levels of these principals' PE perceptions; and what they have to say about the opportunities, challenges and solutions on their school PE. Participants were 92 principals (37 Males, 55 Females) from 12 different school districts of Shanghai. The Adapt Principal Perception on PE Questionnaire ${ }^{\text {Chinese Version (APPPEQ }}{ }^{\text {C.V. }}$ ) was employed for data collection; this questionnaire consists of sixteen items with a 5-points Likert like scale. Key data analyses technich $\rightarrow$ technique was a 2 x 2 (Gender x School-levels) multivariate analysis of variance (MANOVA). Findings included: The principals' PE perceptions appear to be very positive evident by scored high on the APPPEQ ${ }^{\text {C.V. }}$ E.g. Item 5, "Without PE in our school curricula, our students will not be fully developed"; Item 11, "Once PE and daily PA are valued and supported, children will gradually form their active and healthy lifestyle". The MANOVA discovered that: no significant difference in the 'Gender' factor; however, significant differences were found in the 'School-levels' factor: Elementary-school principals scored higher than middle-school principals in 5 items; e.g. Item 3, "PE is an academic discipline and just as important as English, Math and Sciences to our students". While principals at middle-school scored higher than those of the elementary-school in other 5 items; e.g. Items 14, "Safe environment, necessary facilities and equipment is the key for kids to . . "The challenges, opportunities and solutions in their school PE do existed and were analyzed and discussed.
\end{abstract}

Keywords: Challenges; Opportunities; School curricula; Healthy lifestyle; School-levels

\section{Introduction and background}

\subsection{General Introduce to the Problem}

Previous researches have concluded that physical activities (PA) conducted in physical education (PE) programs in schools have been recognized as ideal paths and environments for developing a healthy lifestyle because of the characters of PE programs and the high rate of student enrollment (Chen \& Darst, 2001; Graham, Holt/ Hale \& Parker, 2008; Hagger et al., 2002; Pangrazi, 2007; Sallis \& McKenzie, 1991). With regard to contextual factors, quality PE programs have been reported to be a strong factor influencing students' to take part in PE classes and after school PA. Students' positive attitudes towards PA are likely to be linked with enjoyment, perceived usefulness of the curriculum, and a sense of belonging (Subramanian \& Silverman, 2007). Curriculum with situational interest, such as those that require students to analyze and design offensive and defensive strategies, may foster students' interests in PA (Chen \& Darst, 2001). A learning environment that promotes personal meaning is considered to be important to the development of students' positive attitudes toward PE (Rink, 2010). Children are also likely to have more of a positive outlook toward PE if they are in a learning environment that makes them comfortable and confident (Hagger et al., 2002).

Researchers support the idea that PA relieves stress and increases energy levels in one's body. The following researchers in particular, provided meaningful illustrations and evidence in that regarding: (1) Rothstein (2000) indicated, "Children need exercise to learn. Scientists say it is plausible that by promoting blood flow to the brain, 
physical activity increases cognitive power" (p. B11). (2) Warburton, Nicole and Bredin (2006) found that a healthy body and a healthy mind help students learn better and achieve higher. (3) In a review of literatures concerning the benefits and outcomes of school PE and sports; as a result, the evidences were presented in terms of children's development in physical, lifestyle, affective, social, and cognitive five important domains. Bailey (2006) summarized and suggested that PE and sports have the potential to make significant and distinctive contributions to an individual's development in each of the five domains; including those fundamental movement skills and physical competences, which are necessary precursors of participation PA in her/his later lifestyles. Bailey (2006) further concluded that the contributions and benefits of school PE and sports are not only good for children but also benefit the entire educational system.

\subsection{Introduction to Issues of School PE and PA among Children at all School Levels}

On the other hand, things were not always developing as people expected. Over the years, many health and school PE related research projects have found that lack of necessary PA among children at all school levels is enormously serious and regarded as a major health risk issue, even though since the year of 2000, the trend of school PE has been changed from physical fitness towards promoting and maintaining a healthy lifestyle. The problem is pretty simple, because maintaining a healthy lifestyle and continually participating in physical exercise need time and persistence, a huge challenge to our young generation (e.g. Anderssen, Wold \& Torsheim, 2005; Blair, \& Church, 2004; U.S. DHHS, 2000; Zoeller, 2007).

Moreover, with the progress of human society, the improvement of modern science and; the increasing pressure for students to perform well in the major academic subjects' examinations, the value of PE and other relative subjects (such as arts, music) will be questioned again (Stevens-Smith, Fisk, Williams \& Barton, 2006). Under these new challenges, all parties (school children, parents, and principals) must make their decisions on: whether or not to focus more time on the academic study, get extra lectures/instructions, and find help and particular preparations to perform well on various academic examinations. Stevens-Smith, Fisk, Williams and Barton (2006) explained that it seems that the only choice left for them was to cut the minutes of school PE and to reduce the time spent on regular participation in PA. Particularly, according to Lee (2011), children in China were forced to be involved in PE and PA or sports in the following two ways: 1) maximize their physical activity exercise / sport-training so that they can become professional athletes and earn a living for an accountable future; 2) minimize their physical activity exercise / training intensity and amount of time to focus on academic study so that they can pass various academic exams and get into better schools that will enable them to pursue better futures. These two extreme attitudes towards PE or sports have formed the unique patterns of Chinese PE and PA for many years.

\subsection{Ideas Recommended from the Fields of PE and Health Education Studies}

Over the years, many helpful and good ideas have been recommended from the fields of PE and health education studies. Other than to promote daily PA, researchers and educators suggested that PE should promote daily PA by providing information and skills to students about sports clinics and leagues in the community. Participating in sports helps keep children connected to their communities (Coakley, 2004; Subramaniam \& Silverman, 2007; Stevens-Smith, Fisk, Williams \& Barton, 2006).

Typically, a magnificent example on principals' PE perception might be the study of Sims (2003); in this particular study, the researcher examined the relationships among principals' personal experiences with PE, gender, school levels, and compliance with state PE requirements. The questionnaires of Principal Survey of PE and PE Student Achievement Response Form were used for the data collection. The participants were 243 principals from K- 12 public schools in the state of Alabama, USA. Data analysis techniques involved Pearson Product Moment correlations and factorial analyses. Main significant findings included: a) positive relationship between principals' personal experiences with PE and their value about importance of PE; b) positive relationship between principals' PE value and the level of compliance with state PE requirements; c) Female principals viewed PE and student achievement higher than males; d) Elementary principals viewed student achievement higher than other school levels (grades 6-12) principals.

Furthermore, ideas such as using an interdisciplinary instructive approach that incorporates literacy, math, geography and science into PE classes or lessons, making PE programs more valuable for the young generation have also been recommended by the researchers (e.g. Coakley, 2004; Pangrazi, 2007; Zeng, 2010; Zoeller, 2007). PE professionals can change their images by developing a science-based curriculum, like applying different technology to provide visual, kinesthetic and auditory stimuli in daily lessons and using various teaching styles to bring more fun, and useful skills to meet the needs of diverse learners, as well as the compliance with state or national PE requirements (Graham, Holt/Hale, \& Parker, 2008; Pangrazi, 2007; Sims, 2003; Zeng, 2010). 


\subsection{Current Status and Issues of School PE in Chinese Public Schools}

$\mathrm{PE}$ in China has received a lot more attention from the government now compared to a decade ago. In the New National PE Standards issued by the Ministry of Education to promote physical fitness in public schools (Gann, 2012). Reported by the 'China Radio International', measures include setting aside an hour for PE each day, and if this mandate is not met, and including the results of student fitness tests in annual performance reports for headmasters, principals will have the threat of a demotion in prestige rankings (Gann, 2012). Clearly, this requirement shows that the Chinese government has increased responsibility for the overall well-being of children in China. However, this case also reveals the trouble with adopting broad, universal prescriptions for education reform without considering specific contexts. In this instance, China has adopted and implemented those internationally effective strategies of setting targets that were based on quantitative measurements (Jansen, 2005). Yet, if the intended result of PE were to improve the general health and wellness of students, and to measure scores on fitness tests, would not necessarily reflect it. Additionally, many Chinese parents were concerned that fitness tests may make school environments become too competitive and stressful, particularly surrounding the increased emphasis on academic test scores and so on (Yang, 2011).

\subsection{Explore Importance of the Problem}

Well, no matter how the researchers, educators, media and officials describe, discuss, recommend and make changes in regards to the issues and solutions of school PE and PA, the bottom line is, the principals are the most influential figures to make decisions on how PE and PA will be carried out and implemented in their schools. Although it is difficult to identify generic indicators contributing to overall school effectiveness and successful educational reform, research studies (e.g. Jansen, 2005; Sims, 2003; Yangyu, 2012) have consistently identified the role of the principal as a critical contributing factor or the most influential figure on school operation effectiveness. Principals, therefore, are the key figures in the battle of school PE reform at all levels.

With China becoming the second largest and powerful country economically, PE in their school education system has achieved great progress in recent years. However, compared to other academic disciplines, PE is still viewed as a weak link in their school curricula. With lack of support from a scientific assessment system, sufficient PE teachers, necessary spaces, facilities and equipment, which have impeded the development of students' health, body, and other relative developmental channels.

Regarding China's recent school PE status, Zeng and Meng (2012) have done a survey study on "Comparison of principals' PE perceptions between two different school systems in China". The participants in their study were 138 principals from a "Poor/Developing-region" and a "Rich/Developed-region" of China. The main findings of their study were: a) principals from the two different school-systems perceive PE differently: (a) principals from the "Poor/Developing-region" school system believe PE is less important than other courses; and (b) principals from the "Rich/Developed-region" school system, however, perceive "PE plays a vital role in their school curriculum". When comparing the challenges and opportunities of the two school systems' PE were facing, Zeng and Meng (2012) summarized that: the challenges in school PE, in some degree, there was no remarkable differences; the opportunities for the two school systems' PE, however, have essential differences, e.g.: 1) 'Hardware of school PE has been significantly improved' in the "Rich/Developed-region" school system but "hardware construction of school PE need to be guaranteed' in the "Poor/Developing-region" school system" 2) "As people's living conditions improve, people have paid more attention to their physical health and education" in the "Rich/Developed-region" school system but People on the "whole man development" have a more comprehensive understanding that PE is an irreplaceable discipline and is increasingly prominent in the "Poor/Developing-region" school system. 3) "Large international sports events held in the region have opened huge opportunity for developing School PE' in the "Rich/Developed-region" school system, while "School curriculum reform will provide opportunities for updating and training PE teachers and introducing new sports and PA' in the "Poor/Developing-region" school system and etc.

\subsection{Geography and Education Conditions of the City of Shanghai}

According to Wikipedia, the free encyclopedia (2015), "Enormous Shanghai, on China's central coast, is the country's biggest city and a global financial hub. Its heart is the Bund, a famed waterfront promenade lined with colonial-era buildings". In terms of its education status, "Shanghai took the top spot in the 2009 and 2012 Program for International Student Assessment (PISA), a world-wide study of academic performance of 15-year-old students conducted by the Organization for Economic Co-operation and Development (OECD). Shanghai students, including migrant children, scored highest in every aspect (math, reading and science) in the world." (Dillon, 2010; Wikipedia, the free encyclopedia, 2015). Moreover, "Shanghai has more than 930 kindergartens, 1,200 primary and 850 middle schools. Shanghai is also a major center of higher education in China with over 30 universities and colleges (Sharma, 
2011).

\subsection{Purposes}

Based on the above introductions and descriptions, Shanghai is a remarkable city worthy of study. Additionally, with Shanghai becoming a leader of business and education reform internationally, the city is now facing many opportunities and challenges, a main inquiry would be: whether any unique characteristics exist in regards to their principals' PE perception; therefore, the purposes of this study is to: (a) explore the current status and characteristics of the principals' PE perceptions; (b) obtain the insight into their different PE perceptions between the principals' gender and school levels; and (c) explore what these principals have to say about the opportunities, challenges, and solutions existing in their school PE. The following specific hypotheses would guide the current study: 1) No significant differences would be found on the perception factors between the gender $\rightarrow$ genders of the principals. 2) No significant differences would be found on the perception factors between school levels of the principals. The findings from this study would reveal the first-hand information and a new set of data into the topic of principals' PE perception study from the city of Shanghai.

\section{Methods}

\subsection{Participants}

The participants were 92 principals from 12 different school districts of the city of Shanghai (whereas 37 Males, and 55 Females; age range: 28-55); among them, 51 were Elementary school principals and 41 were Middle school principals. Additionally, these participants had at least three years experiences in her/his position as a principal at the time of collecting data. Before the survey was started, the participants were provided a 'Direction' of how to respond to the questions or items in the APPPEQ $^{\text {C.V. }}$ (Zeng \& Meng, 2012). Furthermore, all participants provided her/his 'Inform Consent Form' when she/he received the questionnaire.

\subsection{The Survey Instrumentation}

The instrumentation was the Adapt Principal Perception on PE Questionnaire -Chinese Version $^{\text {(APPPEQ }}{ }^{\text {-C.V. }}$, Zeng \& Meng, 2012). This questionnaire was employed for data collection and was delivered to 120 principals who came from 12 different school districts of Shanghai. The APPPEQ ${ }^{- \text {C.V. }}$ (Zeng \& Meng, 2012) is comprised of 16 items concerning 'Features of PE discipline'; 'Functions of school PE'; 'Challenges of school PE face'; 'Qualification of teachers'; 'Facilities and equipment' and 'Learning environment' of the school PE. The principals respond to each question on a 5-points Likert type scale, that is: 'Strong-disagree' (score $=1$ ); 'Disagree' (score $=2$ ); 'Somewhat-agree' (score =3); 'Agree' (score $=4)$; and 'Strongly-agree' (score $=5$ ). Moreover, there are three 'open-ended' questions that were designed at the end of the questionnaire; that is, question $17^{\text {th }}, 18^{\text {th }}$ and $19^{\text {th }}$. They asked the participants "what kinds of opportunities, challenges, and solution do you think your schools PE are facing" separately. This type of question allows the principals to stay in their comfort zone and allows them time to write down the answers for the questions (Note. The answers / descriptions obtained from the 'open - ended' questions were defined as qualitative research data).

\subsection{Theories of Perception}

According to Theory of Knowledge. Info (July15, 2015), theories of perception can be classified into the following four categories: a) naive realism; b) representative realism; c) idealism; and 4) phenomenalism. Below are the descriptions for each theory:

On a straightforward view, we directly perceive the world as it is. The way that things look, feel, smell, taste, and sound are the way that they are. We see colors, for example, because the world is colored. This view of perception is called, somewhat dismissively, naive realism.

Plausibly, perception is a lot more complicated than this. Though things may appear to be colored to us, our experiences of color are merely representative the surface properties of objects; the physical properties of certain wavelengths of light and the colored as we experience it are two quite different things.

This has led to representative realism, which suggests that perception is not the passive process that the naive realist suggests, that we do not simply receive information about the world through our senses. Rather, we are actively involved in perception, supplying much of the content of our experiences, and must bear this in mind if we are to know what the world is really like in itself.

More extreme than either naive or representative realism is idealism. Idealists, persuaded by the thought that we have direct access only to our experiences of the world, and not to the world itself, have questioned whether 
there is anything beyond our experiences. A more recent theory that bears some similarities to idealism has also been proposed: phenomenalism. (Resource: Theory of knowledge.info, http://www.theoryofknowledge.info/ theories-of- perception/. July 15, 2015)

\subsection{What PE Perception Means in the Current Study?}

Cherry (2013) defined perception as: "Our sensory experience of the world around us and involves both the recognition of environmental stimuli and actions in response to these stimulus." $\rightarrow$ these stimuli". She stated "through the perceptual process, one gains information about properties and elements of the environment that are critical to one's survival." She continued: Perception not only creates people's experience in a society he or she lives in; it allows him/her to act within that particular environment. Moreover, she described that perception includes five fundamental senses: touch, sight, sound, smell and taste. It also includes what is known as proprioception, a set of senses involving the ability to detect changes in one's body positions and movements. Perception involves the cognitive processes required to process information, such as awareness of their work environment or to detect familiar people or things.

The current study, Principals' PE Perceptions, involves how the principals process the information (includes experiences and knowledge) about school PE; through their perceptual process, they gain or collect information about various properties and elements of the environment that are critical to their survival or duties. That would form their new experience from the school they were in charge of and allow them to make decisions about their school PE.

\subsection{Data Analyses}

Data analysis techniques include descriptive statistics and a 2 Gender (male, female) x 2 School-Levels (Elementary school, Middle school) multivariate analysis of variance (MANOVA). Descriptive statistics technique aimed for reflecting in what degree or the current status of the principals perceive their school PE; while the $2 \times 2$ MANOVA technique designed for reflecting where and in what aspects the principals respond to the survey questions or items differently with regard to their gender and school-levels. Additionally, because of the data obtained from the 'open-ended' questions were defined as qualitative research data, the methods of 'placing data into categories', and 'combining categories into themes' were employed that were described by Marshall and Rossman (1999) and Mikecz, R. (2012).

\section{Results}

The following section presents the findings of the current study. It is structured to address the participants' PE perceptions on their school PE. Out of the 120 questionnaires distributed, only 92 were returned and completed correctly; this represents a response rate of $76.66 \%$. The descriptive statistics reflect the status of the participants' PE perceptions on the PPPEQ ${ }^{\text {C.V. }}$ (Zeng \& Meng, 2012).

\subsection{The Current Status of Participants' PE Perceptions}

As can be seen in Table 1, the top five items that strongly structured the principals' PE perception that were Item 5 "Without PE in our school curricula, our students will not be fully developed", $M=4$.86. Item1 "PE plays a vital role in our school curricula" $M=4.80$. Item 11 "Once PE and daily PA are valued and supported, children will gradually form their active and healthy lifestyle", $M=4.77$. Item 4 "PE is the only discipline that can mold children into healthy whole persons by providing opportunities to develop physically socially and emotionally" $M=4.76$. Item 14 "Safe environment, necessary facilities and equipment is the key for kids to regularly participate in physical activities" $M=4.75$. On the other hand, the bottom five items that had less power structured the principals' PE perception that were Item 8 "Parental supports for daily PA in our school are rarer than ever before" $M=3.43$. Item 7 "Our children are much harder to motivate for participating in regular PA than ever before" $M=3.80$. Item 12 "Having daily PE class is the key to prevent kids from becoming overweight" $M=3.95$. Item 13 "To build up valuable PE programs, having certified PE specialists is the key" $M=4.21$. Additionally, the rest six items in the APPPEQ ${ }^{\text {C.V. }}$ that possess medium influence power that structured the principals PE perception were: Items 3,16, 10, 9 and 15; the mean scores were from 4.73 to 4.36 . 
Table 1. Descriptive Statistics of Shanghai Participants Who Scored on the Principal Perception on PE Questionnaire- ${ }^{\text {Chinese Version }}\left(\text { PPPEQ }^{\text {C.V. }} N=92\right)^{*}$

\begin{tabular}{lcc}
\hline Statements / Items for Responding / Rate & $M(S D)$ & $S U M$ \\
\hline 1. PE plays a vital role in our school curricula. & $4.80(.39)$ & 442.00 \\
2. We can activate and foster the physical activity skills children need through our school & $4.64(.58)$ & 427.00
\end{tabular}
PE programs.

3. PE is an academic discipline and just as important as English, Math and Sciences to our $4.73(.44)$ students.

4. PE is the only discipline that can mold children into healthy whole persons by providing

$4.76(.43)$

438.00 opportunities to develop physically, socially and emotionally.

5. Without PE in our school curricula, our students will not be fully developed.

$4.86(.35)$

6. Obesity is a major health issue in our young generation that can be prevented by improving school PE programs.

7. Our children are much harder to motivate for participating in regular physical activities than ever before.

8. Parental supports for daily PA in our school are rarer than ever before.

$3.80(.96)$

350.00

9. Financial budget cuts have great impact on our PE facility and equipment.

$3.43(1.04)$

427.00

$4.36(.73)$

401.00

10. With certified physical educators teaching PE starting at elementary level will plant

$4.64(.58)$

427.00 good seeds for positive attitude towards PE.

11. Once PE and daily PA are valued and supported, children will gradually form their active and healthy lifestyle.

12. Having daily PE class is the key to prevent kids from becoming overweight.

$4.77(.44)$

439.00

13. To build up valuable PE programs, having certified physical education specialists is the key.

14. Safe environment, necessary facilities and equipment is the key for kids to regularly participate in physical activities.

15. After-school physical activity and sport programs are crucial for kids to become physically educated person.

16. $\mathrm{PE}$ is an ideal course for kids to obtain knowledge, motivation, skills, and confidence to develop and maintain an active and healthy lifestyle.

$M_{\text {Total }}=4.51 \quad S U M_{\text {Grand }}=414.88$

*Note: a) The PPPEQ ${ }^{-\mathrm{C} . V}$.consists of sixteen statements concerning 'Features of PE Discipline', 'Function of School PE', 'Conditions of School PE' and 'Challenges School PE Facing' factors. For each statement, the participant can chose from 'Strongly-agree' (score $=5)$, 'Agree' $($ score $=4)$, 'somewhat -agree' (score $=3)$, 'Disagree' (score $=2)$, or 'Strongly-disagree' (score = 1); b) $M=$ Mean, $S D=$ Standard Deviation, STM = Sum of total mean; c) the highest $S T M$ could be 460.00 , and the lowest $S T M$ could be 92. 00. d) $M_{\text {Grand }}=$ Grand Mean score; and $S T M_{\text {Grand }}=$ Grand Sum of total mean. e) To reduce the length of this article, the questionnaires were omitted here.

\subsection{The Findings from the 2 (Gender) $x 2$ (School Levels) Factorial MANOVA}

The results of the 2 (Gender) x 2 (School Levels) factorial MANOVA were revealed in Table 2. The results showed: no significant difference in the 'Gender' factor $(p>.05), \Lambda=.834, F=.910)$; however, significant differences were found in the 'levels' factor $(p<.024), \Lambda=.696, F=1.997)$; which means that: With regard to the PE perceptions of the principals, the 'School Level' was the determine factor instead of the 'Gender' factor. 
Table 2. The 2 x 2 Multivariate Test (MANOVA) a Comparing on the Principals' Views and Perceptions on their School PE $(N=92 ;$ Males $=37$, Females $=55$ or Elementary School $=51$, Middle School $=41)$.

\begin{tabular}{llllll}
\hline Source & $\begin{array}{l}\text { Wilks' } \\
\text { Lambda }\end{array}$ & $F$ & $\begin{array}{l}\text { Hypo } \\
d f\end{array}$ & $\begin{array}{l}\text { Error } \\
d f\end{array}$ & $P$ \\
\hline Gender & .834 & $.910 \mathrm{~b}$ & 16.000 & 73.000 & .561 \\
Level & .696 & $1.997 \mathrm{~b}$ & 16.000 & 73.000 & .024 \\
Gender * level & .655 & $2.407 \mathrm{~b}$ & 16.000 & 73.000 & .006 \\
\hline
\end{tabular}

Note. ${ }^{\text {a }}$ Design: Intercept + gender + level + Gender $*$ level; ${ }^{b}$ Exact statistic

\subsection{Findings of the Follow-up 2 (Gender) $x 2$ (School Levels) Factorial MANOVA}

According to the research design, after a significant differences effects was found, a follow-up 2 (Gender) x 2 (School Levels) factorial MANOVA for determine where and what the principals' PE perceptions was further conducted; and the findings were present in Table 3. The results showed: principals at elementary school-level scored higher than those principals at middle school-level in Items 1, 3, 5, 11, and 16; e.g., Items 3, "PE is an academic discipline and just as important as English, Math and Sciences to our students" ( $M=4.76$ vs.4.63); Item 5 "Without PE in our school curricula, our students will not be fully developed" ( $M=4.92$ vs. 4.78$)$. While principals at middle school-level scored higher than those principals at elementary school-level in Items 6, 8, 9, 13, and 14. For examples: Items 14, "Safe environment, necessary facilities and equipment is the key for kids to regularly participate in physical activities" ( $M=4.39$ vs. 4.04); and item 6 "Obesity is a major health issue in our young generation that can be prevented by improving school PE programs" ( $M=4.24$ vs. 4.08$)$ and son on.

Table 3. Descriptive Statistics on Principals' View and Perceptions on their School PE $\left(N_{\text {Total }}=92\right.$; Males $=37$, Female $=55$, or E-school $=51, \mathrm{M}$-school $=41$ )

\begin{tabular}{lllll}
\hline Questions/Items & \multicolumn{2}{c}{ Gender - Mean (SD) } & \multicolumn{2}{c}{ Levels - Mean (SD) } \\
\cline { 2 - 5 } & Males (37) & Females (55) & E-Schools $(51)$ & M-Schools $(41)$ \\
\hline Statement 1 & $4.81(.397)$ & $4.80(.404)$ & $4.86(.348)$ & $4.73(.449)^{*}$ \\
Statement 2 & $4.62(.639)$ & $4.64(.552)$ & $4.76(.428)$ & $4.73(.449)$ \\
Statement 3 & $4.73(.450)$ & $4.73(.449)$ & $4.76(.428)$ & $4.63(.471)^{*}$ \\
Statement 4 & $4.84(.374)$ & $4.71(.458)$ & $4.80(.401)$ & $4.71(.461)$ \\
Statement 5 & $4.86(.347)$ & $4.85(.454)$ & $4.92(.272)$ & $4.78(.419)^{*}$ \\
Statement 6 & $4.24(.723)$ & $4.09(1.01)$ & $4.08(1.02)$ & $4.24(.734)^{*}$ \\
Statement 7 & $3.92(.382)$ & $3.73(1.04)$ & $3.55(1.03)$ & $4.12(.781)$ \\
Statement 8 & $3.54(.960)$ & $3.36(.960)$ & $3.16(1.05)$ & $3.78(.936)^{*}$ \\
Statement 9 & $4.43(.647)$ & $4.31(.791)$ & $4.27(.889)$ & $4.47(.513)^{*}$ \\
Statement 10 & $4.65(.558)$ & $4.64(.620)$ & $4.65(.627)$ & $4.63(.536)$ \\
Statement 11 & $4.78(.417)$ & $4.76(.470)$ & $4.88(.325)$ & $4.63(.536)^{*}$ \\
Statement 12 & $4.00(.407)$ & $3.91(.845)$ & $3.90(.755)$ & $4.00(.837)$ \\
Statement 13 & $4.08(.795)$ & $4.29(.685)$ & $4.16(.809)$ & $4.27(.633)^{*} *$ \\
Statement 14 & $4.22(.712)$ & $4.43(.523)$ & $4.04(.755)$ & $4.39(.666)^{*}$ \\
Statement 15 & $4.35(.588)$ & $4.36(.649)$ & $4.31(.678)$ & $4.41(.541)$ \\
Statement 16 & $4.78(.417)$ & $4.69(.466)$ & $4.84(.367)$ & $4.59(.499)^{*}$ \\
\hline
\end{tabular}

Note. $*=$ Significant different at $p<.05$. E-Schools. $=$ Elementary School, M-Schools. $=$ Middle School. Statement 1 to 16 are as the same as in the Table 1 .

\subsection{Findings of the Open-ended Questions}

The three 'open-ended' questions were designed to find out the insight into the principals' view on the current challenges, opportunities and possible solutions for those challenges, opportunities their school PE are facing. The results have been summarized in Table 4, Table 5 and Table 6 below: 
Table 4. Results of Open-Ended Survey on "Current challenges" of School PE (PE) in Shanghai by the Principals ( $N$ $=92$ ) in Shanghai

Question. What kinds of challenges do you think currently your school PE are facing?

Results:

1. The society, parents and students' awareness on school PE is not enough, as long as good grades on the line, this inappropriate understanding has obstructed works need to be carried out on school PE, this is a great challenge.

2. Due to the changes of student's' lifestyle, resulting in decreased physical fitness and movement ability; students' interest in PE is reducing; the number of students of obesity is increasing.

3. Narrow grounds or lands in urban school are the biggest problem. Normal PE and PA cannot be implemented due to the lack of venues and facilities.

4. Current number of students in Shanghai has reached its peak period, over-size PE classes are in everywhere, but the school could not increase the numbers of PE teachers, schools are facing with vacancies in PE teachers.

5. The new challenges from the new national PE standards.

6. In recent years, Shanghai's weather and unfavorable factors from the environment has increased, the school PE are facing more weather challenges than ever before.

7. Physical fitness and movement abilities differences between suburban students urban students have formed a new challenge for school PE.

8. Pressures on theoretical course examinations have made students hard to pay enough attention to PE; little time for them to participate in PA.

9. The society is now still not pay enough attention to PE; and the values of PE and PA are still not been correctly evaluated, and this has affected on the development of school PE.

10. The numbers of Shanghai students' obesity, frail, and sickly are on rising; it is a big challenge worthy of attention.

Note. The results above were through qualitative data analyses methods, such as 'placing data into categories', and 'combining categories into themes' described by Marshall and Rossman (1999) and Mikecz, R. (2012).

Table 5. Results of Open-Ended Survey on "Current Opportunities" of School PE in Shanghai by the Principals ( $\mathrm{N}=$ 92) in Shanghai

\section{Question. What kinds of opportunities do you think currently your school PE are facing? \\ Opportunities:}

1. The government has paid more attention to school PE, increased supervision and input. More attentions have been paid to student physical health, such as, the "sunshine physical activities", "exercise one hour per day" policies have carried out, and to ensure students get suitable PA times.

2. The government has paid more attention to the construction of PE teachers. Produce physical examination mechanisms that regulate PE disciplines that require the cultivation of PE and reserve talents higher requirements, as well as strengthen teaching team's structure and training.

3. The whole society more and more concentrated atmosphere of physical fitness, and public health; teachers and students and parents have a new perception on the school PE. Students and parents have gained enthusiasm on participating in school PE and PA.

4. The rising education level of parents has significantly improved their awareness on universality of PE activities, more and more parents support their children take part in PA and meet the requirements, want their children not only to learn scientific knowledge but also to take part in physical exercise.

5. Physical examination scoring system not only promoted the development of PE teachers, but also guided students to actively participate in PE and PA.

6. To some students like sports, but do not like PE curriculum in school PE programs, that is an good opportunity for reforming PE curriculum and teaching strategies / methods.

Note. The same explanations as in the Table 4. 
Table 6. Results of Open-Ended Survey on "Current Solutions" of School PE in Shanghai by the Principals $(\mathrm{N}=92)$ in Shanghai

\section{Question. What kinds of solutions, do you think, are need to reform your school PE?}

Solutions:

1. The city needs to increase the investment in school PE; include to enhance the status and benefits of PE teachers and improve the conditions for implementing PE classes and necessary school PA under bad weather (e.g., rain, snow, wind, fog, haze, and other).

2. Strengthening the PE teacher and staffs skills and knowledge, improve their business literacy, build a platform to give PE teachers appropriate learning and training opportunities; and establish a new comprehensive and objective PE teacher evaluation system.

3. To take full advantage of the "sunshine physical activities", "exercise one hour per day" policies, providing various physical activities, with suitable times or mandate minutes guarantee that will attract students to participate in PE and PA regularly.

4. PE as an independent discipline should be included in the college entrance examination that will improve PE disciplinary status among all the disciplines, and promote the whole society's awareness of PE discipline.

5. Introduce to all resources of school PE. Learn from those successful modes from developed countries, e.g., after school sport programs, diversity PA programs. Effectively carry out school PE curricular, so that our children can really learnt necessary knowledge and skills about sports and PA that will benefit on developing their Lifelong PE perception and habit.

6. Ensure effectively improve school security incidents system. Such as: 1) Injury regulations on students' injury that occur during PE lesson. 2) School injury treatment clinic. 3) A special division to manage issues relate to injury that occur during PE classes and PA programs. With that will bring positive impacts to facilitate children participate in PA regularly.

Note. The same explanations as in the Table 4.

\section{Discussion}

The current study was designed to explore the following three aspects: a) the status of principals' PE perceptions; b) make comparison analyses to verify if significant differences exist between their gender and school-levels with regard to the principals' PE perceptions; and c) reveal what the principals have to say about the opportunities, challenges, and solutions on their school PE. The first two aspects were through quantitative data analyze techniques and the third aspect employed qualitative data analyze technique.

In early 1990's, Sallis and McKenzie (1991) have pointed out that the public health community has become increasingly interested in the potential contributions of school PE to health of children. School PE has been realized as the best site for the promotion of regular physical activity because up to $97 \%$ of elementary school children participate in some kind of PE program. When school PE programs prepare and help students build-up their perceptions of regularly taking part in lifetime physical activity, the public health benefit would reach its ultimate status. With this concern, Sallis and McKenzie (1991) suggested that physical educators at all school levels were facing new challenges that need their collaborative works with public health professionals to develop and evaluate school PE programs; as the results that would effectively improve the health level of our young generation.

In some degree, the findings of the current study were consistent with the suggestions by Sallis and McKenzie (1991), for examples: the principals rated the following three items as the most important indicators for their school PE: Item 5 "Without PE in our school curricula, our students will not be fully developed." Item 1 "PE plays a vital role in our school curricula." and Item 4 "PE is the only discipline that can mold children into healthy whole persons by providing opportunities to develop physically, socially and emotionally." Moreover, all six 'Solutions' recommended by the principals were alignment with what Sallis and McKenzie (1991) pointed out (see Table 6 for detail). Typically, Solution Number 5 suggested: "Introduce to all resources of school PE. Learn from those of developed countries' mode, such as, after school sport programs, variety PA programs, and actively carry out PE curriculum, so that more students to proceed from the interest, acquired a sport event, to guide students summer vacation fitness, frost their Lifelong PE perception and habit." 
Even though the principals in the current study showed quite positive perceptions of their school PE systems, they have also realized some important issues that must be resolved. The degree of recognition on what will be a good or quality school PE system has significant differences between what the previous researchers suggested and what they believed. One of those examples would be the summarized and suggested by Bailey (2006): PE and sports have the potential to make significant and distinctive contributions to individual's development in the following five domains: Movement skills, physical competences, cognitive competences, affective competences, and social competences. Those are the necessary pre-conditions for an individual forming an active lifestyle and continually take part in regular PA in her/his future life. Additionally, Bailey (2006) also pointed out that school PE and sports are not only good for children but also benefit for the entire educational systems. Obviously, we didn't see these perceptions and recognitions among the participants of the current study. Therefore, we got reasons to summarize this as: In terms of school PE, remarkable differences exist between what the previous researchers recommended and what the participants indicated.

With regards to the challenges of school PE the city of Shanghai are facing, through using qualitative research analyze techniques, the present study has summarized all the information that provided by the principals into 10 different challenges -- as listed in Table 4. In general, all ten challenges are critical to the successful of the reform and improve the school PE in Shanghai; in particular, challenges number 2, 3, 4, and 10 are even more grim or harsh than the other six challenges (see Table 4 for details). To better comprehend how serious of the challenges of school PE the city of Shanghai are facing, we would like to bring the key findings in the challenges of school PE from the city of Nanjing below (Note. That was another survey project on the topic of principals' PE perceptions [N $=88$ ] conducted by Zeng and Meng [2012] in Nanjing - a capital city of Jiangsu province of China):

- $\quad \mathrm{PE} /$ sports resources and facilities are insufficient, and school's PE/sports equipment, facilities and grounds are in contradiction with the needs of students' population.

- Schools' offered times for PE and physical activity are very limited.

- $\quad$ PE teachers' professional knowledge and skills contradict students' favorite emerging sports and physical activity.

- The pressures for children from society and school were too high; schools overloaded their students with homework, which resulted in no time to participate in physical exercise.

- Multivariate lifestyles, especially with popular networks, have made students spend too much time playing on the Internet; that has caused students have no time, no interest, and no energy for physical exercises.

- Contradiction between emphasis on academic education and "holistic education" concept.

- Contradiction between enhancing "fitness awareness" and "health first" philosophy.

- Contradiction between improving enjoyment in PE and enhancing the enthusiasm of students to participate in physical activities.

- Lack of a set of scientific management, such as objective and comprehensive assessment on PE teachers' job.

- $\quad$ PE lacks a systematic system, and the school administrators did not regard PE as playing a crucial role in "whole person education".

No doubt about this, compared to the challenges the two cities were facing, there are many similarities and differences. However, more significant and serious facts were those differences; especially, in Shanghai the following challenges worth to pay close attention and need to be solved before it get worse: a) Due to the changes of student's' lifestyle, resulting in decreased physical fitness and movement ability; students' interest in PE is reducing; the number of students of obesity is increasing. b) Oversize PE classes are in everywhere, but the school could not increase the numbers of PE teachers, schools are facing with vacancies in PE teachers. c) The numbers of Shanghai students' obesity, frail, and sickly are on rising. d) Shanghai's weather and unfavorable factors from the environment has increased, the school PE are facing more weather challenges than ever before. Other than those, the challenges of the two cities are very similar with many aspects need to be improved or solved.

Concerned with the opportunities of school PE the city of Shanghai is facing, using the same qualitative research techniques, the present study also summarized all the information provided by the principals into six different opportunities -- as can be seen in Table 5. After all of this, we found that things are moving in a very positive direction. With regards to this point, it not only can be seen in Table 5, but also shows a pretty consistent trend with the regulations published by the Authorities organization -- the general office of the State Council from the Chinese government. According to Yang (2012), the following were the key items of the regulations: 
1) Primary and middle school students spend one hour each day on schoolyard sports. 2) Time devoted to PE courses and sports should not be reduced or diverted for other use, according to the circular. 3) PE should promote students' interest in sport, develop morality, cooperative spirit, and communication skills and impart basic knowledge and skills. 4) PE should help students develop good exercise habits and a healthy lifestyle. 5) Government-sponsored training programs for PE teachers will be strengthened and teachers should be guaranteed equal opportunities in promotion, welfare and treatment and professional evaluation. 6) Authorities have been urged to step up the construction of sports facilities and called on public sports venues to offer free or discounted admission to young students. 7) Schools nationwide should organize physical examinations for all students annually and report the results to a national database. 8) Health conditions will be considered in performance assessments of schools and relevant government departments.

These solutions proposed by the principals and summarized by the present researchers. Although there are six items only, they are multiple dimensions that have covered all the aspects for a good / quality school PE. It reflected the real wishes of these principals who have been hard worked on the first line in the school education. It also reflected their insight into the current issues and solutions on their school PE. Additionally, although the relevant government departments have published new regulations for school PE, a big gap between the reality and theoretical expectations for school PE do exist, in particularly, it reflected the real situations of the school PE system in the city of Shanghai.

\subsection{Limitations}

The present study explored the status of principals' PE perceptions, the differences between gender and school-levels of the principals' PE perceptions; and what they have to say about the opportunities, challenges and solutions on school PE in Shanghai. Despite we obtained unique findings; and provide a set of quantitative and qualitative data in the research topic of principals' PE perceptions; a few limitations of the present study should be acknowledged. The first is the size of this sample, that is, no matter how to explain it, the 92 participants for a huge urban city is still a quite small size. Second, high school principals were not able to include in the samples. Future studies should try every effort to enlarge the sample size and high school principals should be included as well.

\section{Conclusions}

The participants in the current investigation appeared to have pretty positive principals' PE perceptions evident by scored high on the APPPEQC.V with the following five items strongly structured the principals' PE perception: Item 5 "Without PE in our school curricula, our students will not be fully developed"; item1 "PE plays a vital role in our school curricula"; item 11 "Once PE and daily PA are valued and supported, children will gradually form their active and healthy lifestyle"; item 4 "PE is the only discipline that can mold children into healthy whole persons by providing opportunities to develop physically socially and emotionally"; and item14 "Safe environment, necessary facilities and equipment is the key for kids to regularly participate in physical activities". However, the following five items have less impact on structuring the principals' PE perceptions, which were: Item 8, item 7, item 12, and item 13 (details can be found in Table 1). Furthermore, the rest six items in the APPPEQC.V. possess medium impact on structuring the principals' PE perceptions; that are: Items 3, 16, 10, 9 and 15 (details can be found in Table 1).

Gender is not a determinate factor on the participants' PE perception instead of the school-levels; whereas the principals at elementary school-level in favor at Items 1,3, 5, 11, and 16 than those principals at middle school-level. Principals at middle school-level, however, in favor at Items 6, 8, 9, 13, and 14 than those principals at elementary school-level details can be found in Results section).

With regards to the challenges, opportunities and solutions their school PE are facing, the current study has summarized as ten challenges, six opportunities and six solutions presented in Table 4, 5, and 6. These findings or results are multiple dimensions that covered all the aspects for a good / quality school PE. It reflected the real wishes of the participants of the current study. It also reflected the participants' insight into the current issues and solutions on the school PE system of the Shanghai.

Lastly, people can expect that: Although a big gap does exist between the reality of the school PE in Shanghai and the optimal status for school PE; with the unremitting efforts from the most influential figures / the principals in the school education arena; the school PE of Shanghai will be able to reach / implement its best status in near future.

\section{Acknowledgements}

This research project was funded by the grants of Key Research Project of School Physical Education of Shanghai Municipal Education Commission (SMEC. Grant No. HJTY-2012-B02) and the "Lide Shu-Ren" Shanghai Education 
and Humanities and Social Sciences Research Foundation (SEHSSRF. Grants No. 11000-515100-140), these grants aim at supporting research in school physical education and sports governed by the SMEC. The Principal Investigator of this study would like to express his deepest appreciation to the SMEC and the SEHSSRF; for their great supports to make this study possible.

\section{References}

Anderssen, N., Wold, B., \& Torsheim, T. (2005). Tracking of physical activity in adolescence. Research Quarterly for Exercise \& Sport, 76, 119-129. http://dx.doi.org/10.1080/02701367.2005.10599274

Bailey, R. (2006). PE and Sport in Schools: A Review of Benefits and Outcomes. Journal of School Health, 76, 397-401. http://dx.doi.org/10.1111/j.1746-1561.2006.00132.x

Blair, S. N., \& Church, T. S. (2004). The Fitness, Obesity, and Health Equation: Is Physical Activity the Common Denominator? The Journal of the American Medical Association, Circulation, 292, 1232-1234. http://dx.doi.org/10.1001/jama.292.10.1232.

Chen, A., \& Darst, P. W. (2001). Situational interest in PE: A function of learning task design. Research Quarterly for Exercise and Sport, 72, 285-306. http://dx.doi.org/10.1080/02701367.2001.10608945

Cherry, K. (2013). Perception and the Perceptual Process. Retrieved from http://psychology.about.com/od/sensationandperception/ss/perceptproc.htm

Coakley, J. (2004). Sports in society: Issues and controversies (8th Ed.). McGraw Hill: New York. 125-145. ISBN: 007337654X

Dillon, S. (2010). In PISA Test, Top Scores From Shanghai Stun Experts. New York Times. Retrieved July 15, 2015.

Gann, H. (2012). New standards to promote PE in china. Retrieved from http://nasciinternational.wordpress.com/2012/11/01/new-standards-to-promote-physical-education-in-china/

Graham, G., Holt/Hale, S. A., \& M. Parker. (2008). Children moving: A reflective approach to teaching PE (8th Ed.). Mountain View, CA: Mayfield. ISBN: 0073376450

Hagger, M. S., Chatzisarantis, N. L., \& Biddle, J. H. (2002). A meta-analytic review of the theories of reasoned action and planned behavior in physical activity: Predictive validity and the contribution of additional variable. Journal of Sport \& Exercise Psychology, 24, 3-32.

Jansen, J. D. (2005). Targeting education: The politics of performance and the prospects of 'Education for All'. International Journal of Educational Development, 25(4), 368-380. http://dx.doi.org/10.1016/j.ijedudev.2005.04.009

Lee, A. (2011). The two extremes of Chinese characteristic PE. Retrieved from http://www.chinahush.com/2011/10/26/the-two-extremes-of-chinese-characteristic-physical-education/

Marshall, C., \& Rossman, G. B. (1999). Designing Qualitative Research. Sage Publications, Inc.

Mikecz, R. (2012). Interviewing Elites: Addressing Methodological Issues. Qualitative Inquiry, 18, 482-493. http://dx.doi.org/10.1177/1077800412442818

Pangrazi, R. P. (2007). Dynamic PE for elementary school children (15th Ed.). San Francisco, CA: Benjamin Cummings.

Rink, J. (2010). Teaching PE for learning (6th Ed.). New York: McGraw-Hill.

Rothstein, R. (2000). Are the Three R's Crowding Out P.E.? The New York Times, 11/29/2000.

Sallis, J. F., \& McKenzie, T. L. (1991). PE's Role in Public Health. Research Quarterly for Exercise and Sport, 62 , 124-137. http://dx.doi.org/10.1080/02701367.1991.10608701

Sharma, Y. (October 11, 2011). Jump up "How China is winning the school race". Retrieved from http://www.bbc.co.uk/news/business-14812822

Sims, S. K. (2003). The relationship of principals' perceptions of PE, national standards, student achievement and compliance with state PE requirements in Alabama K--12 public schools. Dissertation Archive. Paper 2500. Retrieved from http://aquila.usm.edu/theses_dissertations/2500

Stevens-Smith, D. A., Fisk, W., Williams, F. K., \& Barton, G. (2006). Principals' Perceptions of Academic Importance and Accountability in PE. International Journal of Learning, 13, 7-12. 
Subramaniam, P. R., \& Silverman, S. (2007). Middle school students' attitudes toward PE. Teaching and Teacher Education, 23, 602-611. http://dx.doi.org/10.1016/j.tate.2007.02.003

Theory of knowledge.info, (July 15, 2015). Retrieved from http://www.theoryofknowledge.info/theories-of-perception/

U.S. Department of Health and Human Services. (2000). Physical activity and health: A report of the Surgeon General. Atlanta, GA: U.S. Centers for Disease Control and Prevention, National Center for Chronic Disease Prevention and Health Promotion.

Warburton, D.E., Nicol, C., \& Bredin, S. S. (2006). Health benefits of physical activity: the evidence. Canadian Medical Association Journal, 174, 801-809. http://dx.doi.org/10.1503/cmaj.051351

Wikipedia, the free encyclopedia. (July 16, 2015). Retrieved from https://en.wikipedia.org/wiki/Shanghai

Yang, L. (2012). China to promote students' PE. Retrieved from http://news.xinhuanet.com/english/china/2012-10/29/c_131938013.htm

Yangyu, L. (2011). Two Youth Soccer Losses Trigger Debate. China Daily. N.P., 26 Oct. 2011. Web. 31 Oct. 2012. Http //www.chinadaily.com.cn/china/2011-10/26/content_13982273.htm\&gt

Zeng, Z. H. (2010). Teaching and Learning in PE Class Settings. LAP Lambert Academic Publishing AG \& Co. KG Saarbrücke, Germany. ISBN (978-3-8383-5446-4).

Zeng, Z. H., \& Meng, W. Y. (2012). A Survey of Principals' View and Perception on School PE in Nanjing (P. R. C.). Paper presented in 2012 International Convention on Science, Education and Medicine in Sport convention. Glasgow, UK, July 2012. In Zeng, Z. H., \& Meng, W. Y. (2014). A Comparison of Principals' Perceptions on School PE. LAP Lambert Academic Publishing AG \& Co. KG Saarbrücke, Germany. ISBN 978-3-659-61081-3. PP. 83-96.

Zeng, Z. H. (2012). Urban Public School Principals' Perception about PE (PE) and Self-Evaluation on Their PE Programs. Asian Journal of PE and Recreation, 18, 82-92.

Zoeller, R. F. (2007). Physical Activity and Obesity: Their Interaction and Implications for Disease Risk and the Role of Physical Activity in Healthy Weight Management. The Journal of the American Medical Association, 1, 437-446. http://dx.doi.org/10.1177/1559827607306889 